\section{Assessment of Gamma Dose Rate for Hypothetical Radioactive Waste Container}

\section{Abstract}

Metallic solid radioactive waste class low-intermediate short lived level waste (LIL$\mathrm{SL} R W$ ) is the main type of radioactive waste generated from decommissioning operations. Transport, storage and disposal regulations require for gamma emitting radioactive waste (mainly by ${ }^{137} \mathrm{Cs}$ isotope), that the dose rate in the proximity of the container should stand below a certain threshold. Also, the conditioning technique (using cementation technique) based on certain matrix with specific ratios should be able to attenuate the gamma radiation activity to the minimum level or to acceptable dosage rate at distance of $1 \mathrm{~m}$ from the container. In this paper, in absence of suitable labs for waste package assessment, hypothetical method present to assess dose rate in safe way, assumption based on metallic waste pieces contaminated with $\left({ }^{137} \mathrm{Cs}\right)$ were conditioned with cement matrix and contained in carbon steel drum volume $220 \mathrm{~L}, 60 \mathrm{~cm}$ diameter then dose rate measurement applied in vicinity of the container. Instead of real contaminated metallic waste $\left({ }^{137} \mathrm{Cs}, \mathrm{D}_{0}=20 \mathrm{mR} / \mathrm{h}\right)$, gamma radioactive point source was positioned in different places in front of cross section of the cemented free metallic waste and gamma dose rates were measured on the outer side of the drum sample using Nal detector dose meter device. Readings showed good attenuation of gamma radiation activity (low dose rates), efficiency of the cement matrix to decrease the dose rate of $\left({ }^{137} \mathrm{Cs}, 0.662 \mathrm{Mev}\right)$ gamma radiation lower to acceptable values and with waste acceptance criteria and regulation.

Keywords: Dose assessment; Radioactive waste; Linear attenuation coefficient

\section{Sabeeha JB, Mohammed GHK, Battawi SM, Falah SHHU, Ahmad JH and Alaa HM}

\author{
Radioactive Waste Treatment and \\ Management Directorate, Ministry of \\ Science and Technology (M.O.S.T), Baghdad, \\ 00964, Iraq
}

\section{Corresponding author:}

Saad Mohammed Battawi

\section{” sab_salim2001@yahoo.com}

Radioactive Waste Treatment and Management Directorate, Ministry of Science and Technology (M.O.S.T), Baghdad, 00964, Iraq.

Tel: $+96-475-06616027$

Citation: Sabeeha JB, Mohammed GHK, Battawi SM, et al. Assessment of Gamma Dose Rate for Hypothetical Radioactive Waste Container. Int J Appl Sci Res Rev. 2017, 4:1.

Received: June 14, 2017; Accepted: June 22, 2017; Published: July 07, 2017

\section{Introduction}

Radioactive waste handling activities are hazardous as concern for both contamination and external exposure; therefore, strict regulations are applied for radiation protection in this field [1]. Dose rate in the vicinity of waste drum has to be kept below certain constraints throughout entire treatment and conditioning process and for the final storage; the dose rate should meet Waste Acceptance Criteria (WAC). Many experiments and tests applied to conditioned radioactive waste drum to check their purposes such as quality of encapsulation process or evaluation the attenuation of gamma activity to minimum level, also to determine and assess the dose rate for conditioned RW drums to storage or disposal [2]. Here one of the test that should be taken in RW management include cut open the package RW (cemented drum) in horizontal direction in safe-secured conditions to examine the enteric of the cemented RW drum and for gamma attenuation determination (shielding function), the cemented bulk will be head to gamma-ray detector or dose rate device and will be taken in contact to the outer side of the drum for quality and safety assessment. In such tests, risks of highly contamination and exposure will be high (radioactive waste dust dispersed in environment). In the absence of controlled lab for such test; hypothetical system present in this work; using metallic waste free of contamination having conditioning process with cementation technique and ${ }^{137} \mathrm{Cs}$ gamma point source was used. The container consists of $15-20 \%$ free metallic waste and $80-85 \%$ of encapsulation material. This drum waste cut open to get two halves piece of cement-waste bulk as in Figure 1. One of the half was cut vertically to get one waste cemented sample to be headed to ${ }^{137} \mathrm{Cs}$ gamma source pointed in many places across the diameter of the sample $(R)$ and dose rate detection held in contact to the bulk outer surface using dosimeter device. This estimation method was necessary in absence of suitable labs for cemented waste as sample test while in waste management activities are very costly and thus the (hypothetic) tests could 
incorporate as much activity as possible to optimize these cots. In addition, many studies could be followed in this field for labs poor in Rad waste drums characterization. The estimation of gamma dose for homogenous waste containers are widely field because of variety of radioactive waste materials for each country and with variety of their activities [3].

\section{Methods}

To achieve the objectives of the present study, Iraq Portland cement and additives are prepared and mixed in certain ratios as Tables 1 and $\mathbf{2}$ show the specification of cementation matrix ratios while Table 3 represent the chemical analysis of container alloy components that used in the waste management facility.

The cement matrix and additives was mixed for $30 \mathrm{~min}$, which were considering enough to achieve good homogeneity. The mixture density $(\rho)$ about $1.675 \mathrm{~g} / \mathrm{cm}^{3}$ dropped into the drum where the clean solid waste was collected in iron basket and centered in the container and left for few moment on the vibrate stage to let gas bubbles escaped from the surface. The sample left for 28 days where the solidification of the cement-waste mixture is completed. Figure 1 show conditioned free waste package after cutting process using electrical machine to get half shape pieces. For gamma dose rate validation, a sample of half-half package waste form was prepared and head to ${ }^{137} \mathrm{Cs}$ gamma source to assumed the waste has been exposed to such gamma radiation rays from many distance $(R)$ along the bulk diameter and that head to different thickness $(x)$ or depth has gamma radiation penetrate through cement matrix shield and reach the detector window. The detection system was dose meter of (Nal) crystal type Ludlum held device with $40 \%$ efficiency of gamma-ray 0.661 Mev, background with $9 \mu \mathrm{R} / \mathrm{h}$ and used at contact with the outer side of waste package. Dose rate measurement and apparatus design in Figure 2, which represents schematic representation of method design.

\section{Results}

The well-known photon linear attenuation coefficient $(\boldsymbol{\mu})$ or shielding equation may be calculated using equation below:

$\mu=\frac{\ln \frac{A_{\mathrm{O}}}{A}}{X}$

Where $A$ the incident gamma-ray activity and $D$ dose rate, which obtained without inserting any sample between the detector and the source and $A, D$, when the incident photons obtained for the cement waste bulk of thickness ( $x$ ). The attenuation coefficient $\mu$ could be calculated in terms of dose rate and activity terms using narrow collimated mono-energetic beam of ${ }^{137} \mathrm{Cs}$ gamma source. The linear attenuation coefficient $\boldsymbol{\mu}$ assumed to be obtained by the following formula:

Table 1 Specification of preliminary mix design.

\section{Water/cement ratio: 0.5}

- $\quad$ Fly ash/cement ratio: 0.3

- $\quad$ Additives: SP703, 1 L/100 kg cement

- Time of mixing: $30 \mathrm{~min}$

Density of cement matrix: $1.675 \mathrm{~g} / \mathrm{m}^{3}$

- Compressive strength: $22 \mathrm{~N} / \mathrm{mm}^{2}$

Table 2 Mass components for Portland cement.

\begin{tabular}{|c|c|c|c|c|c|c|c|}
\hline Components & $\mathrm{CaO}$ & $\mathrm{SiO}_{2}$ & $\mathrm{Al}_{2} \mathrm{O}_{3}$ & $\mathrm{Fe}_{2} \mathrm{O}_{3}$ & MgO & $\mathrm{SO}_{3}$ & $\mathrm{~K}_{2} \mathrm{O}$ and $\mathrm{Na}_{2} \mathrm{O}$ \\
\hline Mass content (percent) & $58-66$ & $18-66$ & $4-12$ & $1-6$ & $1-3$ & $0.5-2.5$ & 1 \\
\hline
\end{tabular}

Table 3 The chemical analysis of container waste alloy using AAS technique.

\begin{tabular}{|c|c|c|c|c|c|c|c|c|c|c|c|}
\hline Element & $\mathrm{Fe}$ & $\mathrm{Mn}$ & $\mathrm{Ni}$ & $\mathrm{Cr}$ & $\mathrm{Cu}$ & $\mathrm{Zn}$ & $\mathrm{Mg}$ & $\mathrm{Ml}$ \\
\hline Concentration & $96 \%$ & $0.11 \%$ & $42 \mathrm{ppm}$ & $0.02 \%$ & $65 \mathrm{ppm}$ & $68 \mathrm{ppm}$ & $10 \mathrm{ppm}$ & $288 \mathrm{ppm}$ & $0.21 \mathrm{ppm}$ \\
\hline
\end{tabular}
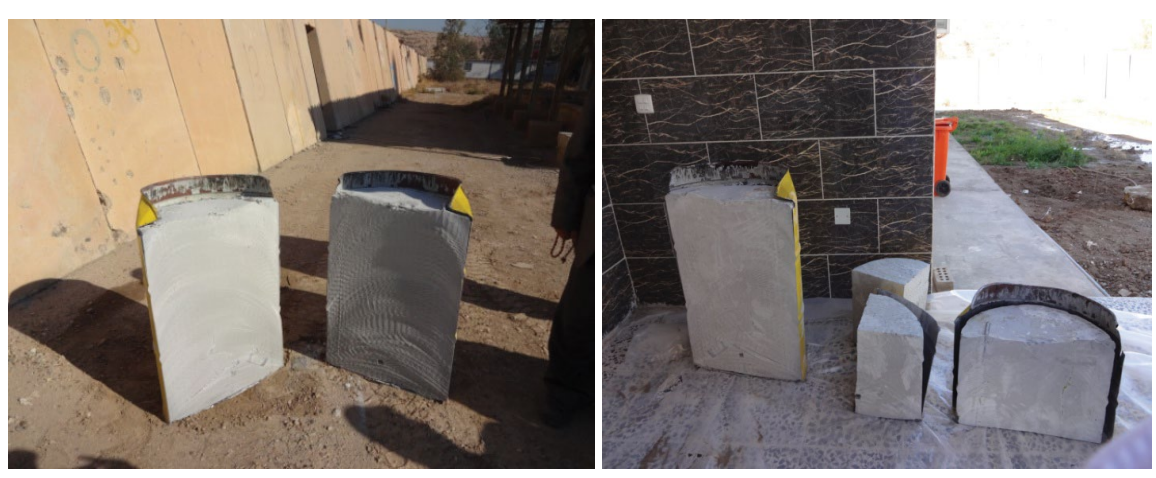

Figure 1 Low magnification optical graphs of cut open conditioned solid waste container. 
$\mu=\frac{\ln \frac{D_{\mathrm{O}}}{D}}{X}$

The dose rates and attenuation coefficient $\boldsymbol{\mu}$ were performed for cemented waste cross section along diameter $(R)$ in relative to their thickness $(\mathrm{x})$. While $\boldsymbol{\mu}$ depend on density of absorber material and cross sections of gamma-ray reactions with absorber material readings show ratios of errors as was expected. By assume equation (2) is valid since the photons in the incident beam are mono-energetic and the beam are narrow [4,5], so for simplicity of the test, build up factor or the mean free path of photons travels were not considered in calculation showed in Tables 3 and 4. From dose rates measurement, activity values were obtained using computer program RadPro 3.2 calculator version 3.24 (2009). The results show in Tables 3 and 4 are displayed in Figures 3-6 for ${ }^{137} \mathrm{Cs}$ gamma source, it can be seen the linear attenuation increased with cement-waste thickness. The plots in Figures $\mathbf{5}$ and $\mathbf{6}$ show the responding relation between the final dose rate of cemented waste bulk and the depth shield along the $R$ axis of the sample for $662 \mathrm{KeV}$ gamma energy [6,7]. The dose rate of the ${ }^{137} \mathrm{Cs}$ contained by cemented waste and carbon steel container specimen was dropped to very low values, which are within Waste Acceptance Criteria (WAC) [8]. Figure 3 show discrepancies in the results, which are mainly due to internal in homogeneity of the waste form, which can alter the dose rate measurement results, it is to be noted that the main hypothesis of this estimation is the homogeneity of the waste form content and the uniformity of the activity distribution. By comparing the dose

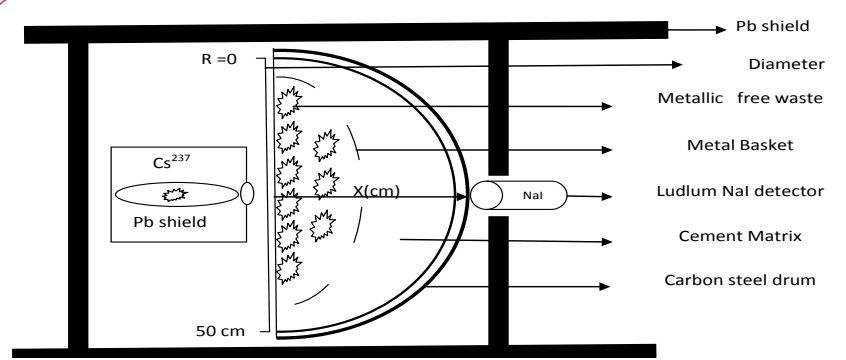

Figure 2 Schematic representation of dose rate measurement to waste container.

Table 4 Dose rate measurements and calculated of linear attenuation coefficient $(\mu)$ in terms of dose rate.

\begin{tabular}{|c|c|c|c|c|c|}
\hline $\begin{array}{l}{ }^{137} \text { Cs Position } \\
\text { (R) }(\mathrm{cm})\end{array}$ & $\begin{array}{c}\text { (D) } \\
(\mu \mathrm{Sv} / \mathrm{h})\end{array}$ & $\begin{array}{c}\text { (D) } \\
(\mu \mathrm{Sv} / \mathrm{h})\end{array}$ & $\begin{array}{l}\text { Thickness of } \\
\text { Cemented Waste } \\
\text { body }(x)(\mathrm{cm})\end{array}$ & $\ln \left(D_{0} / D\right)$ & $\mu\left(\mathrm{cm}^{-1}\right)$ \\
\hline 5 & 26.4 & 7.62 & 19.5 & 1.24 & 0.063 \\
\hline 10 & 20 & 4.86 & 24 & 1.41 & 0.058 \\
\hline 15 & 18.1 & 3.30 & 24.5 & 1.70 & 0.069 \\
\hline 20 & 16.9 & 3.21 & 26.5 & 1.66 & 0.062 \\
\hline 25 & 15.9 & 3.26 & 28.5 & 1.58 & 0.055 \\
\hline 30 & 15 & 3.11 & 29.5 & 1.57 & 0.053 \\
\hline 35 & 15.9 & 3.23 & 28.5 & 1.59 & 0.055 \\
\hline 40 & 16.9 & 3.76 & 26.5 & 1.50 & 0.056 \\
\hline 45 & 18.1 & 4.58 & 24.5 & 1.37 & 0.056 \\
\hline 50 & 20 & 5.80 & 24 & 1.23 & 0.051 \\
\hline 52 & 26.4 & 7.55 & 19.5 & 1.25 & 0.064 \\
\hline
\end{tabular}

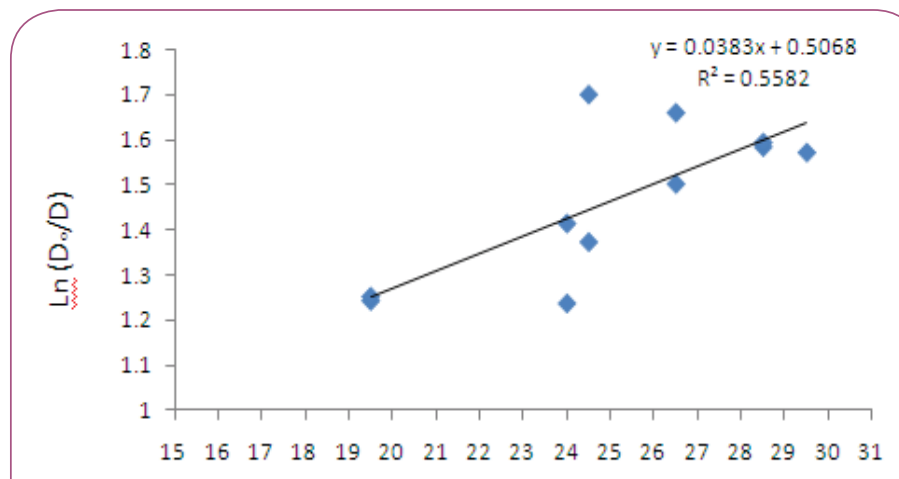

Figure 3 Relation of In ( $\left.D_{\circ} / D\right)$ against cemented waste specimen depth (thickness).

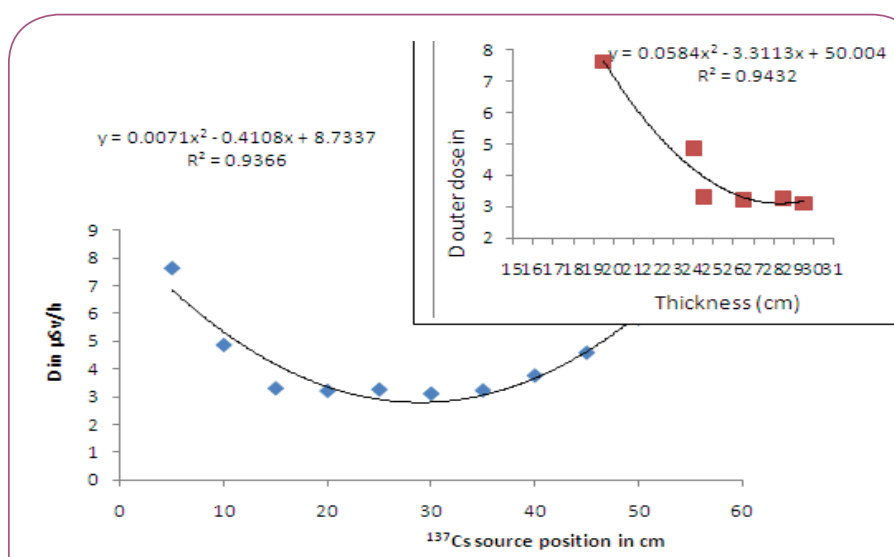

Figure 4 Variation of final Dose rate $\mathrm{D}$ relate to ${ }^{137} \mathrm{Cs}$ gamma source location along the cement waste cross section diameter, $\mathrm{R}(0-52 \mathrm{~cm})$.

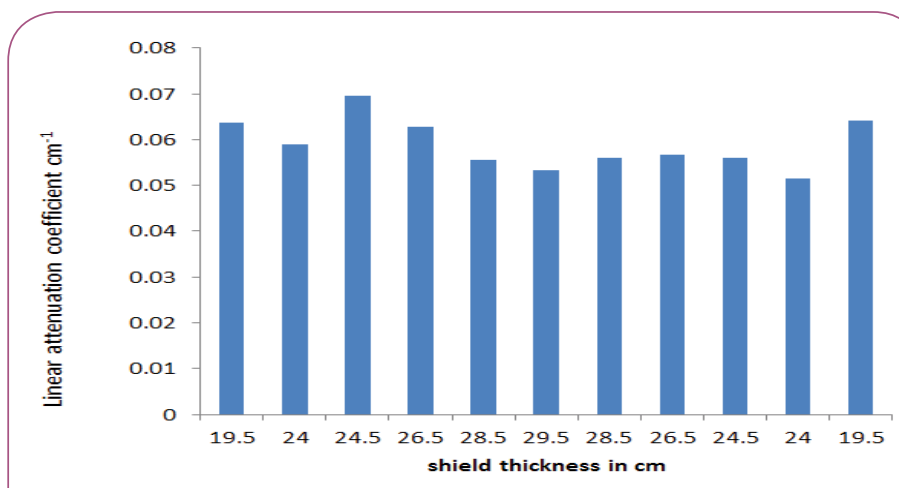

Figure 5 Linear attenuation coefficient $(\mu)$ against shield thickness $(x)$.

rate results, which attenuated by the cement matrix thickness and path length of gamma-ray are with the (WAC) for storage or transport seems acceptable and the conditioning mixture showed a very good suitability and efficiency for solid (liquid) radioactive waste management (Figures 5 and 7; Table 5) [9].

\section{Discussion and Conclusion}

1. During this study, characterization of radioactive waste containers for low and intermediate level waste was implemented. 
2. The maximum linear attenuation coefficient in terms of dose rate or activity were attained for cement matrix ratios incorporate with iron basket for $15-20 \%$ waste, 80 $85 \%$ cement matrix for ${ }^{137} \mathrm{Cs}$ gamma source of initial dose $15 \mu \mathrm{Sv} / \mathrm{h}$ was $0.0531 / \mathrm{cm}$.

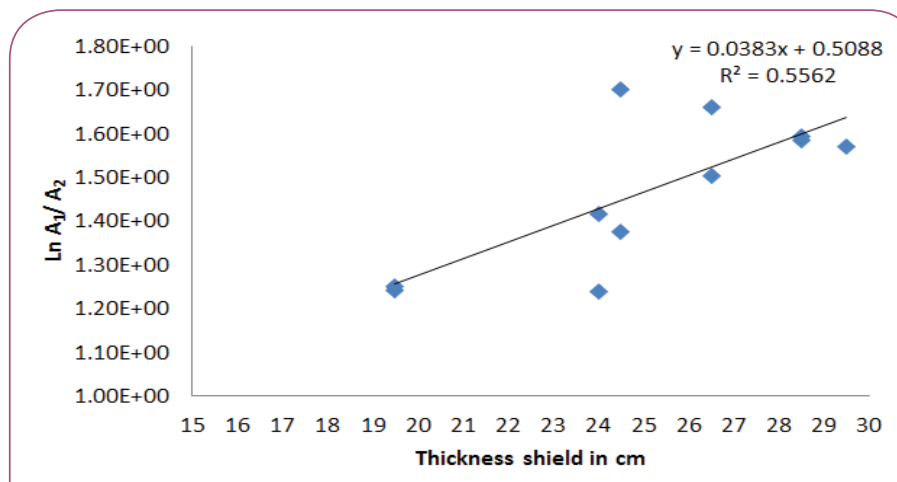

Figure 6 Relation between $\ln A_{\circ} / A$ and thickness shield(x).

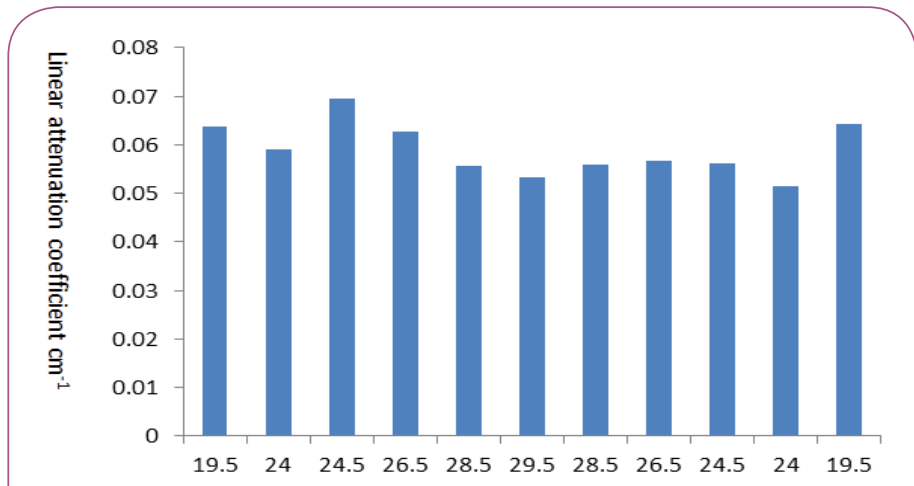

Figure 7 Linear attenuation coefficient $(\mu)$ and thickness shield $(x)$.
Table 5 Calculated of linear attenuation coefficient $(\boldsymbol{\mu})$ in Activity terms (A).

\begin{tabular}{|c|c|c|c|c|c|}
\hline $\begin{array}{c}{ }^{137} \text { Cs Position } \\
\text { R (cm) }\end{array}$ & $\left(A_{1}\right)(B q)$ & $\left(A_{2}\right)(B q)$ & $\begin{array}{l}\text { Depth } \\
\text { (cm) }\end{array}$ & $\ln \left(A_{1} / A_{2}\right)$ & $\mu\left(\mathrm{cm}^{-1}\right)$ \\
\hline 5 & $1.31 E+07$ & $3.79 E+06$ & 19.5 & $1.24 \mathrm{E}+00$ & 6.37E-02 \\
\hline 10 & $1.51 \mathrm{E}+07$ & $3.67 E+06$ & 24 & $1.41 \mathrm{E}+00$ & $5.89 \mathrm{E}-02$ \\
\hline 15 & $1.42 \mathrm{E}+07$ & $2.59 E+06$ & 24.5 & $1.70 \mathrm{E}+00$ & $6.95 \mathrm{E}-02$ \\
\hline 20 & $1.55 E+07$ & $2.95 \mathrm{E}+06$ & 26.5 & $1.66 \mathrm{E}+00$ & $6.27 \mathrm{E}-02$ \\
\hline 25 & $1.69 \mathrm{E}+07$ & $3.47 E+06$ & 28.5 & $1.58 \mathrm{E}+00$ & $5.56 \mathrm{E}-02$ \\
\hline 30 & $1.65 \mathrm{E}+07$ & $3.44 \mathrm{E}+06$ & 29.5 & $1.57 \mathrm{E}+00$ & $5.32 \mathrm{E}-02$ \\
\hline 35 & $1.69 \mathrm{E}+07$ & $3.44 \mathrm{E}+06$ & 28.5 & $1.59 \mathrm{E}+00$ & $5.59 \mathrm{E}-02$ \\
\hline 40 & $1.55 \mathrm{E}+07$ & $3.46 \mathrm{E}+06$ & 26.5 & $1.50 \mathrm{E}+00$ & 5.67E-02 \\
\hline 45 & $1.42 \mathrm{E}+07$ & $3.60 E+06$ & 24.5 & $1.37 \mathrm{E}+00$ & $5.61 \mathrm{E}-02$ \\
\hline 50 & $1.51 \mathrm{E}+07$ & $4.38 \mathrm{E}+06$ & 24 & $1.24 \mathrm{E}+00$ & $5.16 \mathrm{E}-02$ \\
\hline 52 & $1.31 \mathrm{E}+07$ & $3.76 \mathrm{E}+06$ & 19.5 & $1.25 \mathrm{E}+00$ & $6.42 \mathrm{E}-02$ \\
\hline
\end{tabular}

3. The minimum dose rate values was in contact of waste container bulk exposed to ${ }^{137} \mathrm{Cs}$ gamma source was (3.11 $\mu \mathrm{Sv} / \mathrm{h})$ and the maximum dose values was $(7.62 \mu \mathrm{Sv} / \mathrm{h})$ related to the thickness of the penetration depth of the gamma radiation 29.5 and $19.5 \mathrm{~cm}$.

4. The results proved that the cementation matrix (ratios) and the iron basket with the carbon steel container metals have an impact on attenuation performance of gamma radiation beside the bulk density and porosity level of the solidified cement-waste mix.

5. Substantial improvement of about ( 28.86 and $20.73 \%)$ in attenuation performance in term of dose rate ratios at $R$ ( 5 and 30 ) cm for initial dose rate $D_{0}(26.4$ and $15 \mu \mathrm{Sv} / \mathrm{h}$ ) in air of cement waste sample depth was attained for solid waste and using Iraqi Portland cement local product.

6. Solid waste conditioning and treatment utilized successfully due to the structure of open cut cross section of cement waste bulk. 


\section{References}

1 International Atomic Energy Agency (2008) The management system for the processing, handling, and storage of radioactive waste. Safety Guide, No. GSG3.3, IAEA, Vienna.

2 International Atomic Energy Agency (2006) Storage of radioactive waste. Safety guide, No. WS-G-6.1, IAEA, Vienna.

3 Dulama CN, Dulama M, Dobrin R, Pavelescu M (2011) Estimation of the gamma dose rate for homogenous waste containers. Rom J Phys 56: 1136-1142.

4 Dobrin RI, Dulama CN, Toma AL (2004) Shell source method in radwaste assay. Rom J Phys 49: 517-521.
5 Basdevant J, Rich J, Spiro M (2005) Fundamentals in nuclear physics. Springer Science+Business Media, Inc., NY, USA.

6 Maheemeed AK, Hasan HI, AL-Jomaily FM (2012) Gamma-ray absorption using rubber-lead mixtures as radiation protection shields. J Radionanal Nucl Chem 291: 653-659.

7 Mostofinejad D, Reisi M, Shirani A (2012) Mix design effective parameters on $\gamma$-ray attenuation coefficient and strength of normal and heavy weight concrete. Construction and Building Materials 28: 224-229.

8 Treatment Center for Radioactive Waste (2007) NUKEM technology $\mathrm{GmbH}$.

9 International Atomic Energy Agency (1992) Treatment and conditioning of radioactive organic liquids. IAEA-TECDOC-656: 38. 